\title{
Inappropriate modeling of chronic and complex disorders: How to reconsider the approach in the context of predictive, preventive and personalized medicine, and translational medicine
}

\author{
Soroush Seifirad ${ }^{1}$ (D) $\cdot$ Vahid Haghpanah ${ }^{2}$ \\ Received: 16 April 2019 / Accepted: 2 July 2019 / Published online: 31 July 2019 \\ (C) European Association for Predictive, Preventive and Personalised Medicine (EPMA) 2019
}

\begin{abstract}
Preclinical investigations such as animal modeling make the basis of clinical investigations and subsequently patient care. Predictive, preventive, and personalized medicine (PPPM) not only highlights a patient-tailored approach by choosing the right medication, the right dose at the right time point but it as well essentially requires early identification, by the means of complex and state-of-the-art technologies of unmanifested pathological processes in an individual, in order to deliver targeted prevention early enough to reverse manifestation of a pathology. Such an approach can be achieved by taking into account clinical, pathological, environmental, and psychosocial characteristics of the patients or an individual who has a suboptimal health condition. Inappropriate modeling of chronic and complex disorders, in this context, may diminish the predictive potential and slow down the development of PPPM and consequently modern healthcare. Therefore, it is the common goal of PPPM and translational medicine to find the solution for the problem we present in our review. Both, translational medicine and PPPM in parallel, essentially need accurate surrogates for misleading animal models. This study was therefore undertaken to provide shreds of evidence against the validity of animal models. Limitations of current animal models and drug development strategies based on animal modeling have been systematically discussed. Finally, a variety of potential surrogates have been suggested to change the unfavorable situation in medical research and consequently in healthcare.
\end{abstract}

Keywords Predictive preventive personalized medicine $\cdot$ Future healthcare $\cdot$ Animal modeling $\cdot$ Disease modeling $\cdot$ Clinical trial failure $\cdot$ Translational medicine $\cdot$ Chronic diseases $\cdot$ Cardiovascular disorders $\cdot$ Cancer $\cdot$ Toxicology $\cdot$ Drug discovery $\cdot$ Drug development

\begin{tabular}{ll}
\multicolumn{2}{l}{ Abbreviations } \\
3TC & Lamivudine \\
ACS & American College of Surgeons \\
AIDS & Acquired immunodeficiency syndrome \\
AJCC & American Joint Committee on Cancer \\
ALS & Amyotrophic lateral sclerosis \\
APP & Amyloid precursor protein \\
ATLS & Advanced trauma life support
\end{tabular}

Soroush Seifirad

sseifira@bidmc.harvard.edu; sseifirad@gmail.com

PERFUSE Study Group, Division of Cardiology, Department of Medicine, Beth Israel Deaconess Medical Center, Harvard Medical School, Boston, MA, USA

2 Endocrinology and Metabolism Research Center, Endocrinology and Metabolism Clinical Sciences Institute, Tehran University of Medical Sciences, Tehran, Iran

$\begin{array}{ll}\text { AZT } & \begin{array}{l}\text { Azidothymidine (now renamed zidovudine, but } \\ \text { still best known by the abbreviation AZT) }\end{array} \\ \text { CABG } & \text { Coronary artery bypass grafting } \\ \text { CADD } & \text { Computer-aided drug design } \\ \text { CF } & \text { Cystic fibrosis } \\ \text { CHD } & \text { Coronary heart disease } \\ \text { CUMS } & \text { Chronic unpredictable mild stress model } \\ \text { CVD } & \text { Cardiovascular disease } \\ \text { DM } & \text { Diabetes mellitus } \\ \text { EPMA } & \text { The European Association for Predictive, } \\ & \text { Preventive and Personalised Medicine } \\ \text { EPO } & \text { Erythropoietin } \\ \text { ER } & \text { Estrogen receptor } \\ \text { FDA } & \text { U.S. Food and Drug Administration } \\ \text { HDL-C } & \text { High-density lipoprotein cholesterol } \\ \text { HER2 } & \text { Human epidermal growth factor receptor } 2 \\ \text { HIV } & \text { Human immunodeficiency virus } \\ \text { IPF } & \text { Idiopathic pulmonary fibrosis }\end{array}$




\begin{tabular}{|c|c|}
\hline LD50 & Lethal dose, $50 \%$, median lethal dose \\
\hline MI & Myocardial infarction \\
\hline NNND & $\begin{array}{l}\text { Neurological, neuropsychiatric, and neurode- } \\
\text { generative diseases }\end{array}$ \\
\hline $\mathrm{OCP}$ & Oral Contraceptive \\
\hline PM & $\begin{array}{l}\text { Predictive, preventive, and personalized } \\
\text { medicine }\end{array}$ \\
\hline $\mathrm{R}$ & Progesterone receptor \\
\hline QSAR & Quantitative structure activity relationships \\
\hline $\mathrm{RCT}$ & Randomized controlled trial \\
\hline SARS & Severe acute respiratory syndrome \\
\hline SOD-1 & Superoxide dismutase 1 \\
\hline ГЕМ & Effector memory $\mathrm{T}$ cell \\
\hline TGN1412 & $\begin{array}{l}\text { Theralizumab (also known as TGN1412, CD28- } \\
\text { SuperMAB, and TAB08), a humanized mono- } \\
\text { clonal antibody that not only binds to, but is a } \\
\text { strong agonist for, the CD28 receptor of the im- } \\
\text { mune system's T cells }\end{array}$ \\
\hline NM & Tumor, nodes, and metastases \\
\hline & Transactive response DNA-binding protein 43 \\
\hline & $\mathrm{X}$-linked severe combined immunodeficiency \\
\hline
\end{tabular}

\section{Introduction}

In order to have a patient-tailored approach, choosing the right medication, the right dose at the right time point, the standardization and individualization should go hand in hand. Predictive diagnostics, targeted prevention, and personalization of medical services are the main objective of the predictive, preventive, and personalized medicine (PPPM). Translational medicine was introduced recently to emphasize the appropriate translation of knowledge from studies at the bench side to care at the bedside. Economic circumstances and missing political regulations are among the factors resulting in the blockage between the bench and bedside; to these, we should add the applicability of the bench studies as the foundation of clinical investigation and subsequent clinical trials. In order to efficiently indorse the translational medicine as the "catalyzer" for the practical implementation of the accumulated scientific achievements, an appropriate dialogue is essential between three clusters of "clinician, clinical investigator, and PPPM relevant professional groups," "the bench scientists," and "industry and policy-makers" $[1,2]$.

Animal models made a revolution in biomedical research [3]. Plenty of treatment modalities were developed on the basis of animal experimentations. Meanwhile, there is an increasing number of failed clinical trials, particularly on chronic and complex diseases that biased from the results of studies on inappropriate animal models $[4,5]$. It is time to ask whether animal models truly predict human health conditions.

While validity and acceptability of current successful trials and guidelines are debated in the 21 st century because they are not patient tailored, how could we rely on animal models as an appropriate predictor of human conditions?

Simplifying a complex system is inevitable to study the basis of a complex phenomenon. However, simplified models do not reflect all the properties of complex systems [4, 6]. When an animal model is used as the basis of a clinical trial, it is needed to mimic the complex properties of the patients. Otherwise, animal models might be misleading; consequently, a large number of therapeutic modalities might have lost in translation [7]. This study was therefore undertaken to provide shreds of evidence against the validity of animal models. It has been systematically discussed why the authors believe that it is time to re-evaluate the validity of animal experimentations. Although plenty of state-of-the-art disease modeling techniques have been introduced recently, their acceptance and application in the medical science society are scarce; nevertheless validity of these modern modeling techniques needs further evaluation as well. There is a gap between bench and bedside that, unfortunately, has not been appropriately filled with the animal models. In our contribution, we want to provide relevant facts which clearly show that translational medicine and PPPM need accurate surrogate for misleading animal models in order to increase the level of the future healthcare. In this article, we review the knowledge on inappropriate modeling of chronic and complex disorders, which is very important point for the predictive, preventive, and personalized medicine. The translation medicine in this point has to deal with this problem in order to support further and smooth development of PPPM. It is absolutely essential the experts in all fields of medicine, and beyond, are aware of the described problems. The predictions in PPPM and potential preventive actions may very well be compromised if inappropriate modeling is being widely used in numerous cases, let alone the creation of personalized models for an individual patient. There is a great need and potential for fundamental changes in strategies, leading to substantial improvements in future healthcare.

\section{Examples of drug development failures}

Almost $92 \%$ of all drugs found safe and therapeutically effective in animals fail during clinical trials due to either toxicity or inefficacy [7-9]. Half of the mere 8\% U.S. Food and Drug Administration (FDA)-approved drugs must later be withdrawn or relabeled due to severe unexpected side effects [8].

Plenty of significant medical advances have been delayed due to misleading information derived from animal models. For instance, dog experiments delayed coronary artery bypass grafting $(\mathrm{CABG})$ by means of patients' veins, because dog studies falsely showed that veins could not be used in clogged artery segment replacement (bypass) [10]. Similarly, kidney transplantation is not tolerated in dogs while it has an 
acceptable tolerance in humans [11]. Moreover, the toxic effects of statins in animals delayed their clinical use in humans that tolerate them very well [12]. Studies on polio transmission are among other misleading animal studies that delayed discovering currently known facts. For example, studies on monkeys demonstrated that polio transmits via gastrointestinal tract which was wrong [13].

Inappropriate disease modeling using animal models were responsible for a huge number of failures in the history of modern medicine, more examples we summarize here as follows:

\section{Gene therapy: another illusion of scientific revolution}

From 1990, only X-linked severe combined immunodeficiency (X-SCID) gene therapy showed near acceptable results; the other trials failed among several hundred successful gene therapies in animals; however, among ten successfully treated XSCID children, three developed leukemia, and one of them died due to its complications. None of these adverse effects were predicted by animal experiments and prompted the FDA to halt several gene therapy programs in the USA [14, 15]. Hemophilia gene therapy programs were also discontinued in 2004 due to perilous complications such as liver damage which was not predicted in animal studies $[15,16]$.

\section{Myocardial infarction and stroke: just reading the last seen is not enough to comprehend a drama}

Animal models of myocardial infarction (MI) generally do not completely mimic the MI process. Although atherosclerosis models are currently available, MI animal models are usually surgically mimicked by the clumping-reperfusion process. Hence, MI is synthesized with no previous hypoxia, no hypoperfusion, etc. Actually, acute myocardial infarction is the final sequence of the atherosclerosis drama as a chronic process. In the case of MI modeling, the erythropoietin paradox certified inappropriate modeling of $\mathrm{MI}$ as a complex phenomenon [3]. Almost 500 drugs underwent trial for stroke; among them, only aspirin and early recombinant tissue plasminogen activator did not fail $[17,18]$.

\section{Diabetes mellitus: it is not all about the insulin}

Operational implementation of PPPM perceptions to diabetes mellitus (DM) care is due long ago. The European Association for Predictive, Preventive and Personalised Medicine (EPMA) emphasizes the need to debate the large-scale complex approach for diabetes care, especially those with comorbid pathologies such as cardiovascular disease (CVD), cancer, and neurological, neuropsychiatric, and neurodegenerative diseases (NNND) [1, 19, 20].
Streptozotocin-induced diabetes models are one of the widely used diabetes models [21]. Diabetes is a chronic process with several genetic as well as environmental risk factors. There are several abnormalities in diabetes patients, including impaired insulin secretion, increased insulin resistance, endothelial dysfunction, increased oxidative stress, and impaired antioxidant defense system, and all of them occur in a prolonged period of time [22]. Additionally, diabetes is usually accompanied by a variety of comorbidities such as obesity, atherosclerosis, and other. None of the abovementioned parameters has been reflected in the streptozotocin mouse model of diabetes. Zucker rats are better examples of DM which could be replaced; at least, these obese animal models represent metabolic syndrome, and diabetes occurs after a period of time in these obese rats [23].

\section{Cancer: we are the underdog, with no doubt}

Despite plenty of promising preclinical studies on cancer treatments, roughly $85 \%$ of early clinical trials for novel drugs fail, and only half of the medications that enter phase 3 studies will become approved for clinical application [7, 8, 24]. Our efforts in the war against cancer were not encouraging in terms of therapeutic approaches; in fact, it was preventive approaches that showed promising effects. Genetic, molecular, cellular, and immunologic differences between models and human beings made them poor prognostic modalities [4]. False positivity of rodent studies in this case was around $95 \%[25,26]$. In reality, rodent cancer models is believed to be invalid and financially indefensible [27]. Only $8 \%$ success rate in the translation of cancer studies has been reported; actually, $85 \%$ of all clinical trials failed before starting phase 3 trials. Among studies which enter phase 3, half of them were withdrawn [28, 29]. Only a little number of these studies are adopted and the others are being withdrawn after sacrificing their victims [7, 30]. Most of the cancer animal models are suffering from inappropriate modeling. Inoculation of malignant cells (cell lines) is the most common current method of malignancy modeling. This model does not reflect the prolonged complex process of developing a malignancy. Recently, knocked out animal models and animal models with special mutations have been introduced [7, 29, 31]; although these models sufficiently mimic genetic background of malignant tumors, the epigenetic role and the role of environment were not reflected in these models. Additionally, there are several probable genotypes for a single phenotype of malignancy.

For instance, extremely high heterogeneity among breast tumors is well documented. Hence, Jaak Janssens beautifully stated the question as: "should we speak about breast cancers instead of cancer?" [32, 33].

Genomic guidance gradually becomes the standard for diagnostics in cancer care $[33,34]$. For example, in response to 
the growing knowledge about molecular characteristics of breast cancer subtypes and the need for personalized approach to the patients, the American Joint Committee on Cancer (AJCC) dramatically revised their latest edition (8th edition, last updated January 25, 2018) of breast cancer staging manual. The 8th edition of the AJCC tumor, node, and metastase (TNM) breast cancer staging system delivers a flexible platform for prognostic classification based on traditional anatomic factors, which may be modified and enhanced with respect to patient biomarkers and other prognostic panel data. Compared to the previous version, a variety of genetic and molecular factors has been incorporated to the current version, among them are HER2, estrogen receptor (ER), progesterone receptor (PR), and also multigene panels such as Oncotype DX $[35,36]$. There is a difference between "silent" carriers of tumor lesions and patients who are predisposed to disease development and progression; a "fertile" microenvironment that supports the tumorigenesis, tumor invasion, and metastasis can distinguish between them. The mechanisms "fertilizing" the microenvironment for the cancer advancement are not addressed in animal models but it is very well addressed by innovative PPPM strategies in cancer $[1,37,38]$.

\section{Neuroscience: we are human beings and it is because of our brains}

The complexity of the human brain and behavior makes psychological aspects of neuroscience one of the most challenging areas of disease modeling.

\section{Depression: it is neither all about men nor about male rats}

Depression as a prevalent brain dysfunction in modern society is a real challenge for physicians and scientists. Stress exposure model, chronic unpredictable mild stress model (CUMS), maternal deprivation model, sleep deprivation model, and social defeat, are among the well-known animal models of depression. Almost always, rat and mouse are used to model depression [39-50]. Forced swimming test, tail suspension test, open field test, and hot plate test are among the most known tests of evaluating depression in the previously mentioned models [50-54]. Although these are creative and decent models, however, how could someone compare a so-called depressed male rat behavior and attitude with the depression in Franz Kafka or Friedrich Nietzsche?

Additionally, depression is different in men and women, in terms of its perception as well as mechanisms. Furthermore, post-menopausal depression is catecholamine-dependent, while depression in women in the productive age is serotonin prominent. That is why venlafaxine is suitable for elderly depressed women, and fluoxetine and sertraline have nothing to do with them but are the drug of choice for depressed men [51-53]. All these happened since studies on depression were almost always conducted exclusively on men; unfortunately, scientists preferred to avoid menstrual cyclic depressions, and eliminated women, even when raised FDA approval.

Amyotrophic lateral sclerosis: animal models were based on the rare form of the disease instead of the prevalent form

For years, scientist studied amyotrophic lateral sclerosis (ALS) misleading model of superoxide dismutase 1 (SOD-1) which is responsible for only rare cases of ALS instead of transactive response DNA-binding protein 43 (TDP-43) which is responsible for the majority of cases. Hence, a large number of currently failed trials need re-evaluation with new models of the new gene [55-57]!

\section{HIV: where animal models were completely useless}

Unfortunately, there is no acceptable animal model for human immunodeficiency virus (HIV) and acquired immunodeficiency syndrome (AIDS) [58]. Until the year 2006, more than fifty preventive vaccines and over thirty therapeutic vaccines were showed successful against HIV and AIDS in primate studies; regrettably all of them has failed in human clinical trials. Both efficacy and toxicity of current known treatments for HIV such as zidovudine (AZT), lamivudine (3TC), and protease inhibitors are the results of in vitro studies using human white blood cells [59].

\section{Genetic diseases}

Although called "genetic disease," they are also the consequence of interactions between the defected gene(s), and other genes, and also the environment, that is why so many of animal models failed to mimic phenotype of genetic disorders; for example, cystic fibrosis (CF) transgenic mice failed to mimic pancreas blockage and lung infections that happen in humans with CF [60, 61].

\section{Teratogenicity}

Animal models are used for understanding disease mechanisms and potential new treatments rather than predicting what will happen in humans. That is why toxicity and teratogenicity studies usually fail. Among 1396 different substances studied, it has been shown that half of the human teratogens are safe in animals. Conversely, almost half of the safe human agents are dangerous (teratogen) in animals, and 1/3 tested agents showed varying results in different species [62-64].

\section{Toxicity}

Theralizumab (TGN1412) catastrophe is one of the best examples of low power of animal models in prediction of toxicity of drugs [65-67]. Cigarette smoking failed to produce lung 
cancer in animals [4]. The same happened with asbestosis models $[68,69]$ and also diagnostic X-ray carcinogen effects $[70,71]$. Effect of alcohol on fatty liver cirrhosis is another example [72]. This is one of the most unreliable issues in animal modeling; lethal dose, 50\%, (LD50) is highly unreliable. Animals' age, sex, strain, and weight have substantial effects on the results of toxicity studies, and due to huge differences of approximately all animal models, their results are extremely unreliable [73]. In vitro studies have been recently validated to replace LD50 [74, 75]. Among hundreds of known carcinogens in mice since 1980 , only 15 proved to be a carcinogen in humans.

\section{Discussion}

In this section, the etiology of the abovementioned drug development failures has been systematically discussed. None of the complexity, chronicity, age, comorbidities, sex, genetic similarity, and environmental factors have been appropriately modeled in most of the current animal models. Subsequently, the dangers of animal modeling are discussed.

\section{Complexity}

Given plenty of abovementioned examples, it is clear that the complex character of human diseases was not presented in most animal models. Diabetes, atherosclerosis, and dementia are all examples of chronic complex diseases that are modeled with extremely simplified acute approaches.

With no doubt, neuroscience is the most conflicting field of animal modeling. Compared to any other organ, complexity of the human brain is not comparable with animal models not even in primates. Neuropsychological disorders in human are not comparable to animals at all. That is why a large number of drug discoveries in this field were the result of direct human observations. A large number of current neuropsychiatric medications were initially studied for other diseases and serendipitously discovered by observation of their side effects. For example, amantadine was originally developed to prevent influenza but was found to improve symptoms including tremor, akinesia, and rigidity in people with Parkinson disease [76-78]. Chlorpromazine, currently prescribed for its antipsychotic properties, was traditionally introduced as a possible additive to potentiate general anesthesia [79].

Furthermore, familial, social, and cultural factors cannot be modeled in animals.

\section{Wrong nomination is misleading}

Nominating a simplified model such as a transgenic mouse model as a true model of a given disease is dramatically misleading, especially when a complex multifactorial disease is being studied. As mentioned before, even single-gene diseases are the result of a transaction of a mutated gene with the wild genes and the environment. SOD-1 mutation transgenic model of ALS is a good example. First of all, this model is extremely sensitive to infection; second, SOD-1 mutation is only responsible for less than $3 \%$ of the patients, and surprisingly, transgenic mouse which has 23 copies of this gene is known as the standard ALS model in the majority of studies. Conclusively, SOD-1 ALS transgenic models were representative of rare disease forms instead of prevalent mutations. This model represents a very aggressive presentation of ALS which does not respond to almost any treatment except for SOD inhibitors. Thus, current protocols of ALS treatment are a range of broad-spectrum antibiotics and general antiinflammatory agents. Cochrane database analyses showed that even in the case of riluzole, the sole FDA-approved treatment of ALS, mean survival of the patients increased only up to 2 3 months [18].

The same problem happens when we incorrectly call a streptozotocin model as a diabetes model, or clumping reperfusion procedure as a surrogate of a true myocardial infarction.

Even in the presence of similar phenotypes of diseases, different genotypes and different pathophysiologic mechanisms in the patients compared to the models could critically impair the models' prediction power that is essential for PPPM to work with. This issue is more challenging when we are studying diseases with vague and wide definition such as idiopathic pulmonary fibrosis (IPF). Idiopathic refers to our loss of knowledge about the exact mechanism of the disease; in fact, IPF might refer to several different unknown diseases with different mechanisms that were clustered under a sole name. Fibrosis could be the end-product of several unknown genetic, microbial, viral, and rheumatologic pathways yet to be discovered. Hence, how could we identify a bleomycin or paraquat-induced pulmonary fibrosis mouse model, like an IPF model? We should also keep in mind that pathophysiology of an idiopathic disease like IPF might be extremely diverse in different populations that further lower the predictability of our simplified models.

From a PPPM point of view, it is time to redefine medical terms. As stated by Janssens, "Should we speak about breast cancers instead of cancer?" $[32,33]$. Parallel to the personalized clinical approach, our disease models should be defined precisely. Heterogeneity of cancer types that are currently mistakenly clustered in a single term calls for dedicated approaches with their characteristics from bench to bedside. There is a significant difference between triple negative breast cancer in a premenopausal woman and triple positive breast cancer in a postmenopausal woman in terms of management planning, chemotherapy selection, chemotherapy response, metastasis tendency, and general outcome. As a result, our models should reflect the differences appropriately to make 
the foundation of clinical research reliable and practical in PPPM.

\section{Chronicity is not reflected in most of the current models}

Plenty of human diseases are complex and chronic, while the counterpart models are not reflecting their chronic character. Internal validity of experimental studies is dramatically affected by the ignorance of the chronic character of the diseases.

Myocardial infarction models are the best example of a chronic process which was not modeled accurately. That is why plenty of drug development studies failed in this issue. Myocytes which were exposed to chronic hypoxia due to hypoperfusion activate compensatory pathways to protect themselves from hypoxia. Hypoxemic preconditioning explains the reasoning behind the smokers' MI paradox. It also explains why erythropoietin (EPO) is a protector in acute-induced MI in healthy myocytes but not in the adapted myocytes. Increased EPO secreted during chronic hypoxia previously saturated EPO receptors and implemented its cell protective effects; in fact, extra EPO, in this case, will not augment extra cell protection [3].

As another example, acute lesions produced by means of stereotaxic surgery or toxin infusion to mimic Parkinson in mice have almost nothing to share with progressive, chronic, degenerative pathophysiology of Parkinson in human beings.

\section{Age}

Age is one of the almost always ignored factors in disease modeling. Even in a given species normal physiology, the pathophysiology of diseases and response of the organism to environment and drugs is different in young and old organism. And by adding to this fact also inter-species, intra-species discrepancies, you will find how current disease models are useless. For example, clofibrate, nafenopin, phenobarbital, and reserpine cause cancer in old but not young rats [80-82]. Different depression pathophysiology in pre- and postmenopausal women is another example. Menopausal status barely modeled if any in animal modeling. As another example, it has been repeatedly shown that premenopausal women with breast cancer have a higher risk for brain metastasis development. Thus, the premenopausal status at the time of breast cancer diagnosis is considered as an additional risk factor for the brain metastatic lesions which were not reflected in animal models of breast cancer $[32,38]$. It is time to ask how could we rely on the results of animal experiments with such significant inter- and intra-species discrepancies.

\section{Sex}

Actually, disease perception and even definition in human beings might be different in either sex. Pathophysiology of diseases (i.e., depression), pharmacokinetic, and drug response in men and women is different. In order to avoid menstrual cycles and mood disturbances of women, most of the studies on depression eliminated women from their study group.

\section{Mouse}

Availability of rodents, short gestation and easy reproduction, resistance, costs, easy maintenance, and small size have made mouse the flagship of animal models. Compared to the larger animals such as primates who are much better representation of human beings, mice were much more widely used in experimental studies. Actually, a high percentage of our knowledge comes from male mouse studies which raise concerns for a so-called male mouse bias.

Although in some single-gene disease such as Huntington's disease, there is a good correspondence between human and murine models. In terms of other environmental injuries such as trauma and burns, and also in systemic inflammation and endotoxemia, coefficient between human and murine models was less than $1 \%$ [28]. As another example, 18 out of 23 anticancer vaccines failed in clinical trials [7]; it has been hypothesized that these were due to higher levels of circulating immunosuppressive cytokines and several immunologic checkpoints in humans that might not be present in rodents. Males and mice are more resistant, compared to the other species (rabbit) and females. Additionally, they are cheaper, working with them is easier, and need smaller labs.

Additionally, inter-species genetic variations might further complicate the results of animal studies. Genetic differences in mouse models might interfere with the results of animal experimentations. Although this might be decreased by increasing sample sizes and sacrificing more animals, but this trend is accompanied by several ethical concerns and is not recommended.

\section{Environment}

There is an extremely sensitive interaction between genes, epigenetic regulations, and the environment that governs a sensitive balance between health and illness [6]. Regrettably, environment and its effect on the organism have been tremendously neglected in healthcare and disease modeling. "PPPM approach aims to develop appropriate knowledge and technological skills for promoting affordable strategies in the emerging fields of environmental risk factors, epidemiology, healthy lifestyle, individualized nutrition, food technology and culture in a framework of cost-effective healthcare $[1,34] . "$ 
Most of the animal models are kept in a clean standard environment, while this environment does not reflect the conditions in real life. For example, smoking as a prevalent habit has not been reflected in most of the animal experiments. That is why oral contraceptives (OCP) killed plenty of women, most of them smokers, and that is why riluzole induced liver damage in smokers; all of these tragic events were not predicted in experimental studies [83, 84]. Interaction with the other widely used medications such as proton pump inhibitors is another example which is not generally studied in models. For instance, riluzole and pantoprazole co-consumption increases the likelihood of liver damage in ALS patients.

Animals are maintaining in a standard clean environment which is not comparable to real life. For instance, TGN1412 (anti-CD-28 monoclonal antibody) made an unpredicted human catastrophe. After administration, it tends to multi-organ failure due to an unpredicted immune response in the patients. Subsequently, it has been shown that $\mathrm{CD} 4^{+}$effector memory $\mathrm{T}$ cells (TEM) were responsible for the cytokine release syndrome (CRS) and multi-organ failure in the studied patients [28]. As rodents were stored under very clean circumstances, they had no multiple exposures to infectious microorganisms; hence, TEM cell accumulation did not happen in them. Unfortunately, studies in monkeys also failed to show these adverse effects because of the diversity of their immune system compared to the human. Surprisingly, it was later discovered that in macaque monkeys (Cynomolgus macaques), $\mathrm{CD}^{+} \mathrm{T}$ cells lose $\mathrm{CD}-28$ expression during differentiation into TEM cells [65-67].

\section{Dangers of animal modeling}

As mentioned above, the most dangerous aspect of relying on animal models is their low, if any, predictive potential related to the toxicity of the therapeutic drugs. There are plenty of human catastrophes that happened because of this. The other dangerous aspects of animal studies are infections that are transferred from animals to people working in the research facilities with these animals. Several animal-lab researchers suffered or died due to animal microbes. At least, 16 lab workers have been killed by the Marburg virus. Ebola outbreaks in American monkey colonies infected a number of lab workers [85]. We believe that year by year, a huge amount of time, money, and resources are wasted by inappropriate animal modeling. Around 106,000 people die every year from adverse reactions to animal-tested drugs, while 2.2 million people are seriously injured annually. Furthermore, working with animals is accompanied by several serious problems, such as the production of new serotypes, genetically drifted viruses, and contamination of biological products. For example, Simian virus 40 infected polio vaccines; as a known carcinogen, it has infected millions of Americans [86]. Although it is still doubtful, there are reports that hypothesized that HIV might be the result of polio vaccine production using monkey tissues or the product of cancer and biologic weapon research in the early 1970s [87-90].

There are several potentially infectious agents, especially virus and prions of nonhuman grafts and tissues that might be transmitted to humans. Severe acute respiratory syndrome (SARS) outbreaks might be the results of remodeling and combination of zoonosis with human viruses. Prion diseases are also extremely dangerous for us and there is a high likelihood of transfection to animal lab workers and receivers of animal lab products like animal-derived vaccines. The same might happen in genetic engineering labs, while during the production of recombinant proteins, other unknown infectious agents might contaminate their products. Contamination with animal viruses and prions has been dramatically decreased after human tissue culture introduction [91]. Meanwhile, animal cell cultures are still being practiced in several labs [92].

Predictability of some models is assumed to be around $50 \%$; instead of modeling, we might flip a coin and save money and innocent animals. Honestly, ethics committees are not taking care of animals and plenty of them are sacrificed for nothing. Animal study designing is not as accurate as human trials, there is no registration for experimental studies, almost none of them is blind, and standard anesthesia is not practiced in many institutions. Brutal handling of animals is quite prevalent in laboratories around the world. Regrettably, more than 100 million animals are killed in animal labs annually.

Publication bias is another critical concern of animal experiments. Since they are not registered, negative results are rarely presented. Even in clinical trials, fewer than one in five cancer RCTs are being published. Since negative results are not being published, animal studies generally overvalue, by about $30 \%$, the likelihood that a treatment might be effective $[7,18]$. It is time to register animal studies, just like clinical trials.

\section{Three conclusive examples}

\section{Neurosciences and Alzheimer}

A brief review of the literature will disclose several socalled animal models of Alzheimer, but a deeper look at Alzheimer models reveals that these models generally cover only one aspect of the complex character of this neurodegenerative disease [93]. A large number of responsible factors have been suggested for developing Alzheimer and among them are aging, inflammation, oxidative stress, vascular abnormalities, and amyloid depositions. Surprisingly, lifestyle, nutrition, education, academic achievements, and even career are also related to Alzheimer development [94-96]. Now it is time to 
ask, how could we synthesize such a complex, chronic, multi-factorial disease of an extremely complex organ (human brain) in a mouse model? Is a transgenic model such as amyloid precursor protein transgenic mouse model a suitable model for human Alzheimer disease [97-99]? It has been shown that patients with Down syndrome develop Alzheimer earlier than the normal population due to having three copies of chromosome 21 and hence three copies of amyloid precursor protein (APP) gene. However, does it mean that Alzheimer in Down syndrome is equal to Alzheimer in elderly?! Does an Alzheimer model, which was developed by means of applying a mitochondrial toxin to a rat, is a good representative of Alzheimer in a Nobel laureate? How could we compare cognitive impairment in animals and human beings? We have to change the names of our models. Amyloid precursor protein transgenic mouse model is not an Alzheimer model. It is nothing but three copies of amyloid precursor protein deposition in the brain of a mouse. Conclusively, targeting a single aspect of a multifactorial disease such as Alzheimer will not appropriately model such a multifactorial chronic complex disease. In fact, none of age, oxidative stress, education, and other responsible genes were reflected in APP models of Alzheimer. It seems that in neuroscience, it is inevitable to fade out the stress of primary animal models. Weight of human trials is not comparable with the animal studies. Animal models might be misleading, if we do not revise our models' names and if not revising the concept of disease modeling instead of risk factor modeling.

PPPM approaches patients instead of diseases; for a patient-tailored approach, complex characteristics of the patients should be addressed precisely [1, 2, 34]. In order to provide reliable practical information, preclinical studies should implement PPPM concepts and hence model diseases with respect to their detailed characteristics of the patients. It is quite sophisticated and literally impossible to model complex characteristics of human neuropsychiatric disorders in animal models.

\section{Wound healing}

Both, modifiable risk factors (such as stress, smoking, inappropriate alcohol consumption, malnutrition, obesity, diabetes, and cardiovascular disease) and nonmodifiable risk factors (such as genetic diseases and aging), have been identified in the process of impaired wound healing, which calls for implementation of PPPM approach in this area [100]. Individual risk factors, causality, functional interrelationships, molecular signature, predictive diagnosis, and primary and secondary prevention are all crucial in approach to impaired wound healing [34].

On the other hand, animal models of wound healing are extremely simplified; almost none of comorbidities and risk factors of impaired wound healing has been modeled on them. Among the important risk factors that were not presented in the majority of models are aging, smoking, malnutrition, obesity, diabetes, and cardiovascular disorders [100, 101].

\section{Myocardial infarction}

As a final example, let us take a short look to the MI/ stroke models and evaluate the abovementioned confounding factors which were not taken into account while modeling $\mathrm{MI} /$ stroke.

a. First of all, most of the patients with MI/stroke are old, while most of the animals are young.

b. Most of the patients with stroke are suffering from several comorbidities such as hypertension, obesity, and diabetes while models are healthy animals which acutely underwent an arterial temporary blockage procedure.

c. A large number of patients with stroke are smokers; none of the animals are.

d. Female animals are usually underrepresented in experimental studies but the patients come from both sexes.

e. Most of the models are rats and mice and biologically closer species have been rarely used, which increases inter-species discrepancies and decreases the validity of these biologically distant models.

f. Timing is a matter of fact in $\mathrm{MI} /$ stroke treatment. Pretreatment and immediate treatment are prevalent in models, while in the real world, there is almost no pretreatment for MI/stroke. It happens suddenly and generally only hours after the MI/stroke, treatment will start for most of the patients.

g. In experimental studies, the efficacy of treatment in models is evaluated by infarct volume, while the clinical relevance of infarct volume with the patients' outcome is in doubt. Infarct size has been shown to have a moderate correlation with the patients' clinical status and outcome [3].

h. Preconditioning is of great importance specially in terms of applying recombinant cell protectors such as EPO; nevertheless, preconditioning has not been modeled in animal models of stroke and MI.

i. Percentage of cells undergo stunning, and the location of the infarct plays a crucial role in clinical presentation and outcome of the patients. None of these has been reflected in stroke models. 
Old habits die hard: why do animal models still exist?

Why do animal models still exist? First of all, it is difficult to change roles, terms, and conditions. People are happy with their routines. Some people are making money with animal models; currently, animal production for experimental studies seems to be a treasured industry.

Particularly, animal experiments may provide a legal sanctuary for pharmaceutical companies. In our opinion, pharmaceutical companies, by means of presenting experimental studies as scientific evidence, can find their way to escape from complaints. Moreover, it seems that only after having their money back and when plenty of patients have suffered from unexpected side effects (as evidenced in plenty of phase 4 studies) they will withdraw selling their products, while, unfortunately, most of them are not willing to compensate for their fault. Huge amounts of money and resources are wasted, and pharmaceutical companies are not those who missed their resources. Actually, by providing false scientific pieces of evidence using inappropriate animal models and selling their drugs, they usually have their money back before phase 3 and 4 studies reveal hazards and inefficacy of their products. When the society complains against this malpractice, these inappropriate pieces of evidences will likely protect them from being sued.

Compared to the clinical trials, the publication of animal experiments is much easier. Experimental studies are also less expensive compared to human studies and less time-consuming. Scientist could produce new and interesting findings in a short time with a small amount of money, time, and energy. They need a pretty small research group, with no need to owe clinicians, and guarantee academic improvement for faculty members and lab directors. The more you publish, the more you are a scientist! Furthermore, many of old-school researchers currently working with animals as experts in this field do not like to learn new methods such as tissue culture. Animal experiments are lucrative since there are several direct grants for animal research. Additionally, there are less ethical investigations during the conduction of the study and at the time of publication. Surprisingly, animal studies appear more scientific compared to clinical investigation. A very small number of clinician scientists exist, and tunnel vision of PhDs and lack of holistic knowledge of the diseases and its complex character are real challenges for current investigations. Finally, at the moment, there is still a vast lack of knowledge and expertise in cutting-edge nonanimal techniques.

Although we have learned a lot from animal experiments, a large number of our studies are not fruitful and might be misleading. Careful application of animal models is advised and a replacement in the form of novel state-of-the-art technologies is required for disease modeling. Malpractice in animal modeling was such a huge catastrophe that it made some scientist admit that "animal experiments are part of medical history, but history is where they belong."

\section{Recommendations and suggestions for solutions}

The approach of alternatives to animal models was first described in 1957 by Hume and Russell [102], which mostly covered the ethical issues of animal modeling. In 1959, Russell and Burch proposed a number of strategies to make the animal testing further humanly, which was presently identified as three Rs (reduction, refinement, and replacement) [103].

This concept reduces the use of animals in research and refines pain and distress caused during the biological investigations. Furthermore, animal models must be replaced with alternative techniques [104]. These techniques supply alternatives for toxicological, chemical, and pharmacological experiments. Time efficiency and cost-effectiveness are among the advantages of these strategies [105-108]. Application of in vitro human cancer cell lines, as less costly, more reliable alternatives of animal models are warranted.

Alternative methods and models could be categorized as living and non-living systems [107, 109]. Living systems refer to systems based on animal or human components such as cell, tissue, and organ cultures and systems based on organisms including microorganisms, lower vertebrates, and invertebrates. Non-living systems such as biochemical and physiochemical systems, mathematical and computer models (in silico analysis) [110], and epidemiological data on human can also be applied when there is adequate information accessible $[83,107,111,112]$. A number of alternative methods are listed in Table 1.

\section{Importance of clinical investigations}

Understanding and management of human diseases should start with and terminate in human observations [113]. Hepatitis, ulcerative colitis, rheumatic fever, typhoid fever, appendicitis, and hyperparathyroidism are all among samples of successful human-human study pathways.

\section{Epidemiologic population base studies}

Framingham identification of coronary heart disease risk factors is the best example of a critically important massive human cohort [114, 115]. Human observations, population-based studies, proteomics, next-generation 


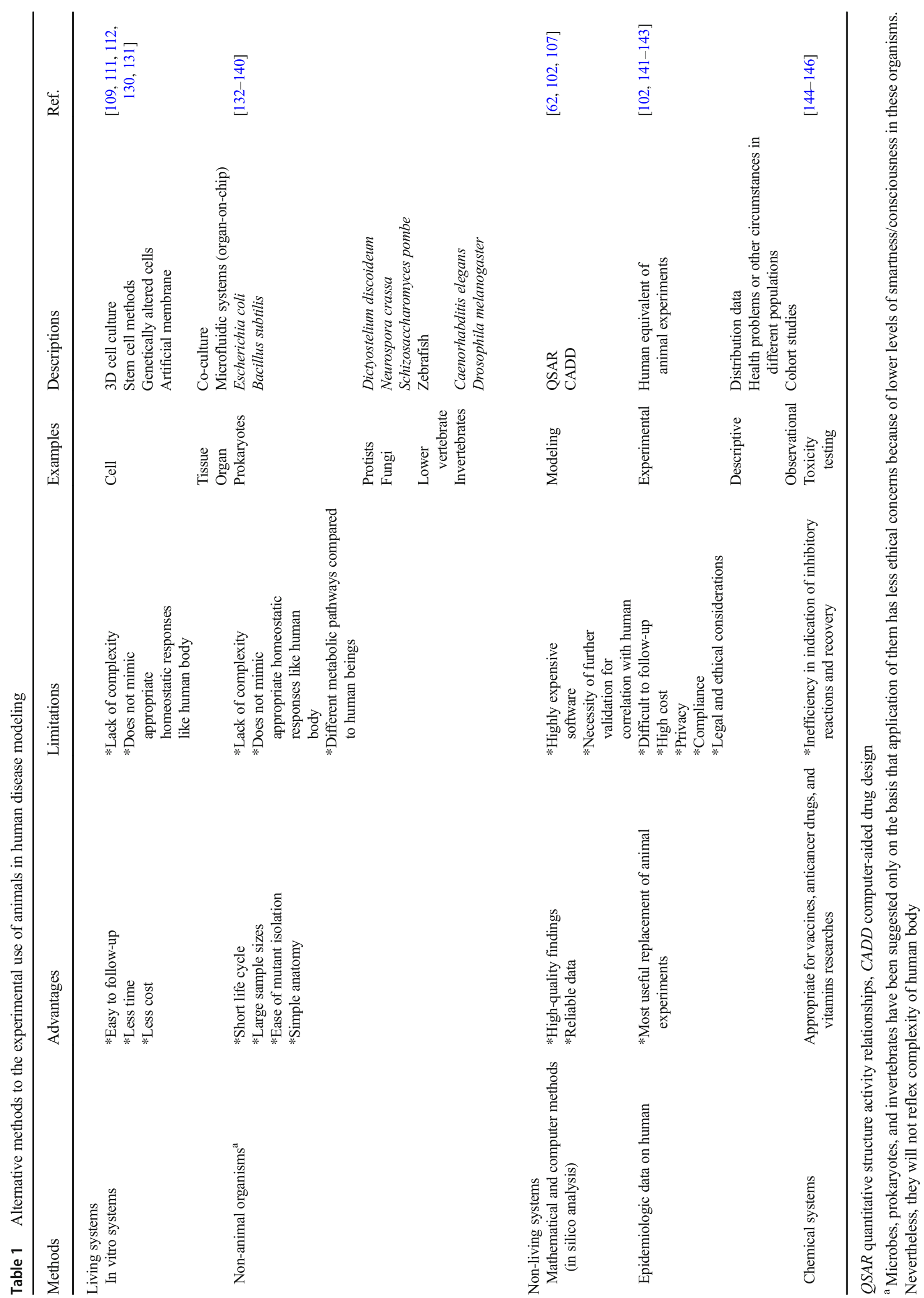


sequencing, whole genome sequencing, post-marketing surveillance, phase 4 trials, side effects observations, network meta-analysis, and Mendelian randomization are among promising novel methods and techniques that can replace animal modeling.

\section{Mendelian randomization}

Mendelian randomization, a novel genetic-epidemiologic approach, may identify a causal link between risk factor and disease, in the presence of confounding factors. Mendelian randomization studies raised major concerns regarding what we believed to be a true causal relationship [116]. For example, courtesy of Mendelian randomization studies, the causal relationship between high-density lipoprotein cholesterol (HDL-C) and coronary heart disease (CHD) is in doubt now; this might explain why plenty of HDL-targeted medications failed to protect patients from developing CHD. Meanwhile, we should keep in mind that just like any other newly presented method, Mendelian randomization has its own limitations yet to be uncovered [117-121].

\section{Autopsies and biopsies}

Most of our current knowledge in Alzheimer, DM, appendicitis, and heart disease is the result of studies on autopsies and biopsies. For example, the development of colon cancers from adenomas was not observed in leading colon cancer animal models $[122,123]$.

\section{Medical education}

Animal labs should be eliminated from educational programs. For example, American College of Surgeons (ACS) presented trauma man simulator to replace animals and human cadavers for the Advanced Trauma Life Support (ATLS) program [124-126].

\section{Phase 0 studies: microdosing}

One out of four drug development failures is because of pharmacokinetic issues such as penetration into the target organ or absorption; microdosing with sensitive tests could solve this problem and eliminate these failures, and help us to save our patients, our money, and innocent animals in labs [127-129]. The results of microdosing studies showed $70 \%$ correspondence with the results from full-dose studies. Nevertheless, like any other novel technique, there is a likelihood of publication bias in the published literature.

\section{Conclusion}

PPPM calls for a patient-tailored approach as choosing the right medication, the right dose at the right time point. This approach may not be achieved unless taking into account clinical, pathological, environmental, and psychosocial characteristics of the patients. In order to accurately model the patients and make relevant predictions, it is necessary to reflect all complex characteristics of the patients into our models. Unfortunately, none of the complexity, chronicity, age, comorbidities, sex, genetic similarity, and environmental factors has been appropriately modeled in most of the current animal models. Hence, current animal models should be extensively revised and/or replaced by novel surrogates to achieve this goal.

There might be plenty of agents, potentially safe in humans, that were not studied in people due to observed toxicity in animals. Also, there might be plenty of missed potential treatments which did not show efficacy in animals and hence never studied clinically; as mentioned above, plenty of currently approved treatments were delayed because of misleading animal models. Hence, we have to look back and re-evaluate hundreds of potential treatments. Some agents might not show efficacy in animals or might be lethal for them while they are well tolerated in humans and could be curative.

Using inappropriate animal models can hardly be accepted if we want to improve the system of healthcare in the future. The surrogates for animal models are gradually emerging and we have to take care that they are vigorously tested and, if passed, used in predictive modeling, disease modeling, and therapy modeling.

\section{Study limitations}

In order to be as comprehensive as possible and cover a wide range of diseases, it was not possible to systematically review all the literature. With plenty of keywords and diversity of discussed studies, it was inevitable to apply a narrative approach rather than a systematic approach to review the literature. A narrative literature review can often include an element of selection bias.

Plenty of suggested surrogates are still in their embryonic period and need further investigation.

Acknowledgments Authors would like to thank Dr. Hilda Samimi and Dr. Mahmood Naderi for their scientific advices.

Author contribution Idea: Soroush Seifirad (SS) and Vahid Haghpanah (VH) 
Literature review: SS

Drafting article: SS except for suggestions which were written by both SS and VH

Final review and approval: SS and $\mathrm{VH}$

\section{Compliance with ethical standards}

\section{Consent for publication Not applicable.}

Ethical approval Not applicable. This is a theoretical appraisal; neither patients nor animals were involved in this research.

Competing interests The authors declare that they have no competing interests.

\section{References}

1. Golubnitschaja O, Baban B, Boniolo G, Wang W, Bubnov R, Kapalla M, et al. Medicine in the early twenty-first century: paradigm and anticipation-EPMA position paper 2016. EPMA J. 2016;7:23. https://doi.org/10.1186/s13167-016-0072-4.

2. Golubnitschaja O, Costigliola V, EPMA. General report \& recommendations in predictive, preventive and personalised medicine 2012: white paper of the European Association for Predictive, Preventive and Personalised Medicine. EPMA J. 2012;3(1):14. https://doi.org/10.1186/1878-5085-3-14.

3. Seifirad S. An emerging need for developing new models for myocardial infarction as a chronic complex disease: lessons learnt from animal vs. human studies on cardioprotective effects of erythropoietin in reperfused myocardium. Front Physiol. 2014;5: 44. https://doi.org/10.3389/fphys.2014.00044.

4. Greek J, Shanks N. Thoughts on animal models for human disease and treatment. J Am Vet Med Assoc. 2009;235(4):363; author reply 4-5. https://doi.org/10.2460/javma.235.4.363.

5. Hackam DG. Translating animal research into clinical benefit. BMJ. 2007;334(7586):163-4. https://doi.org/10.1136/bmj. 39104.362951 .80

6. Seifirad S. A comprehensive model for the asthma paradox: is asthma a protective or a risk factor for malignancy? Med Hypotheses. 2019;130:109268. https://doi.org/10.1016/j.mehy. 2019.109268

7. Mak IW, Evaniew N, Ghert M. Lost in translation: animal models and clinical trials in cancer treatment. Am J Transl Res. 2014;6(2): 114-8.

8. Arrowsmith J. Trial watch: phase III and submission failures: 2007-2010. Nat Rev Drug Discov 2011;10(2):87. doi:https://doi. org/10.1038/nrd3375.

9. Arrowsmith J. Trial watch: phase II failures: 2008-2010. Nat Rev Drug Discov. 2011;10(5):328-9. https://doi.org/10.1038/nrd3439.

10. Domingo RT, Fries CC, Sawyer PN, Wesolowski SA. Peripheral arterial reconstruction: transplantation of autologous veins. Trans Am Soc Artif Intern Organs. 1963;9:305-11.

11. Hume DM, Merrill JP, Miller BF, Thorn GW. Experiences with renal homotransplantation in the human: report of nine cases. $\mathrm{J}$ Clin Invest. 1955;34(2):327-82. https://doi.org/10.1172/ JCI103085.

12. Hajar R. Statins: past and present. Heart Views. 2011;12(3):1217. https://doi.org/10.4103/1995-705X.95070.

13. Dowdle WR, Birmingham ME. The biologic principles of poliovirus eradication. J Infect Dis. 1997;175(Suppl 1):S286-92.

14. Hackam DG, Hackam AS. Translation of genetic discoveries into clinical therapies. Ann Intern Med. 2008;148(3):246-7.
15. Marwick C. FDA halts gene therapy trials after leukaemia case in France. BMJ. 2003 Jan 25;326(7382):181.

16. Marshall E. FDA halts all gene therapy trials at Penn. Science. 2000;28;287(5453):565,567.

17. Juni P, Altman DG, Egger M. Systematic reviews in health care: assessing the quality of controlled clinical trials. BMJ. 2001;323(7303):42-6.

18. van der Worp HB, Howells DW, Sena ES, Porritt MJ, Rewell S, O'Collins V, et al. Can animal models of disease reliably inform human studies? PLoS Med. 2010;7(3):e1000245. https://doi.org/ 10.1371/journal.pmed.1000245.

19. Duarte AA, Mohsin S, Golubnitschaja O. Diabetes care in figures: current pitfalls and future scenario. EPMA J. 2018;9(2):125-31. https://doi.org/10.1007/s13167-018-0133-y.

20. Golubnitschaja $\mathrm{O}$. Time for new guidelines in advanced diabetes care: paradigm change from delayed interventional approach to predictive, preventive \& personalized medicine. EPMA J. 2010;1(1):3-12. https://doi.org/10.1007/s13167-010-0014-5.

21. Furman BL. Streptozotocin-induced diabetic models in mice and rats. Curr Protocols Pharmacol. 2015;70(1):5.47.1-20. https://doi. org/10.1002/0471141755.ph0547s70.

22. King A, Bowe J. Animal models for diabetes: understanding the pathogenesis and finding new treatments. Biochem Pharmacol. 2016;99:1-10. https://doi.org/10.1016/j.bcp.2015.08.108.

23. Shiota M, Printz RL. Diabetes in Zucker diabetic fatty rat. Methods Mol Biol. 2012;933:103-23. https://doi.org/10.1007/ 978-1-62703-068-7_8.

24. Morgan P, Van Der Graaf PH, Arrowsmith J, Feltner DE, Drummond KS, Wegner CD, et al. Can the flow of medicines be improved? Fundamental pharmacokinetic and pharmacological principles toward improving phase II survival. Drug Discov Today. 2012;17(9-10):419-24. https://doi.org/10.1016/j.drudis. 2011.12.020.

25. Lave LB, Ennever FK, Rosenkranz HS, Omenn GS. Information value of the rodent bioassay. Nature. 1988;336(6200):631-3. https://doi.org/10.1038/336631a0.

26. Ennever FK, Lave LB. Implications of the lack of accuracy of the lifetime rodent bioassay for predicting human carcinogenicity. Regul Toxicol Pharmacol. 2003;38(1):52-7.

27. Omenn GS, Stuebbe S, Lave LB. Predictions of rodent carcinogenicity testing results: interpretation in light of the Lave-Omenn value-of-information model. Mol Carcinog. 1995;14(1):37-45.

28. McGonigle P, Ruggeri B. Animal models of human disease: challenges in enabling translation. Biochem Pharmacol. 2014;87(1): 162-71. https://doi.org/10.1016/j.bcp.2013.08.006.

29. Ruggeri BA, Camp F, Miknyoczki S. Animal models of disease: pre-clinical animal models of cancer and their applications and utility in drug discovery. Biochem Pharmacol. 2014;87(1):150 61. https://doi.org/10.1016/j.bcp.2013.06.020.

30. Dwan K, Altman DG, Arnaiz JA, Bloom J, Chan AW, Cronin E, et al. Systematic review of the empirical evidence of study publication bias and outcome reporting bias. PLoS One. 2008;3(8): e3081. https://doi.org/10.1371/journal.pone.0003081.

31. Hakem R, Mak TW. Animal models of tumor-suppressor genes. Annu Rev Genet. 2001;35:209-41. https://doi.org/10.1146/ annurev.genet.35.102401.090432.

32. Polivka J Jr, Kralickova M, Polivka J, Kaiser C, Kuhn W, Golubnitschaja O. Mystery of the brain metastatic disease in breast cancer patients: improved patient stratification, disease prediction and targeted prevention on the horizon? EPMA J. 2017;8(2):119-27. https://doi.org/10.1007/s13167-017-0087-5.

33. Janssens JP, Schuster K, Voss A. Preventive, predictive, and personalized medicine for effective and affordable cancer care. EPMA J. 2018;9(2):113-23. https://doi.org/10.1007/s13167-0180130-1. 
34. Golubnitschaja O, Kinkorova J, Costigliola V. Predictive, preventive and personalised medicine as the hardcore of 'Horizon 2020': EPMA position paper. EPMA J. 2014;5(1):6. https://doi.org/10. 1186/1878-5085-5-6.

35. Giuliano AE, Connolly JL, Edge SB, Mittendorf EA, Rugo HS, Solin LJ, et al. Breast cancer-major changes in the American Joint Committee on Cancer eighth edition cancer staging manual. CA Cancer J Clin. 2017;67(4):290-303. https://doi.org/10.3322/ caac. 21393

36. Giuliano AE, Edge SB, Hortobagyi GN. Eighth edition of the AJCC cancer staging manual: breast cancer. Ann Surg Oncol. 2018;25(7):1783-5. https://doi.org/10.1245/s10434-018-6486-6.

37. Golubnitschaja O, Debald M, Yeghiazaryan K, Kuhn W, Pesta M, Costigliola V, et al. Breast cancer epidemic in the early twenty-first century: evaluation of risk factors, cumulative questionnaires and recommendations for preventive measures. Tumour Biol. 2016;37(10):12941-57. https://doi.org/10.1007/s13277-0165168-x .

38. Smokovski I, Risteski M, Polivka J Jr, Zubor P, Konieczka K, Costigliola V, et al. Postmenopausal breast cancer: European challenge and innovative concepts. EPMA J. 2017;8(2):159-69. https://doi.org/10.1007/s13167-017-0094-6.

39. Ellison GD. Animal models of psychopathology. The lownorepinephrine and low-serotonin rat. Am Psychol. 1977;32(12):1036-45.

40. Paterson NE, Markou A. Animal models and treatments for addiction and depression co-morbidity. Neurotox Res 2007;11(1):1$32,1$.

41. Czeh B, Fuchs E, Wiborg O, Simon M. Animal models of major depression and their clinical implications. Prog Neuropsychopharmacol Biol Psychiatry. 2016;64:293-310. https://doi.org/10.1016/j.pnpbp.2015.04.004 .

42. Yan HC, Cao X, Das M, Zhu XH, Gao TM. Behavioral animal models of depression. Neurosci Bull. 2010 Aug;26(4):327-37.

43. Fuchs E, Fliugge G. Experimental animal models for the simulation of depression and anxiety. Dialogues Clin Neurosci. 2006;8(3):323-33.

44. Harro J. Animal models of depression vulnerability. Curr Top Behav Neurosci. 2013;14:29-54. https://doi.org/10.1007/7854 2012_221.

45. Jesberger JA, Richardson JS. Animal models of depression: parallels and correlates to severe depression in humans. Biol Psychiatry. 1985;20(7):764-84.

46. Matthews K, Christmas D, Swan J, Sorrell E. Animal models of depression: navigating through the clinical fog. Neurosci Biobehav Rev. 2005;29(4-5):503-13. https://doi.org/10.1016/j. neubiorev.2005.03.005.

47. McArthur R, Borsini F. Animal models of depression in drug discovery: a historical perspective. Pharmacol Biochem Behav. 2006;84(3):436-52. https://doi.org/10.1016/j.pbb.2006.06.005.

48. McKinney WT. Animal models of depression: an overview. Psychiatric developments. 1984;2(2):77-96.

49. Neumann ID, Wegener G, Homberg JR, Cohen H, Slattery DA, Zohar J, et al. Animal models of depression and anxiety: what do they tell us about human condition? Prog Neuropsychopharmacol Biol Psychiatry. 2011;35(6):1357-75. https://doi.org/10.1016/j. pnpbp.2010.11.028 .

50. Overstreet DH. Modeling depression in animal models. Methods Mol Biol. 2012;829:125-44. https://doi.org/10.1007/978-161779-458-2 7.

51. Dalla C, Pitychoutis PM, Kokras N, Papadopoulou-Daifoti Z. Sex differences in animal models of depression and antidepressant response. Basic Clin Pharmacol Toxicol. 2010;106(3):226-33. https://doi.org/10.1111/j.1742-7843.2009.00516.x.

52. Ma L, Xu Y, Wang G, Li R. What do we know about sex differences in depression: a review of animal models and potential mechanisms. Prog Neuropsychopharmacol Biol Psychiatry. 2018;89:48-56. https://doi.org/10.1016/j.pnpbp.2018.08.026.

53. Palanza P. Animal models of anxiety and depression: how are females different? Neurosci Biobehav Rev. 2001;25(3):219-33.

54. Renaud A. Animal models of depression. Soins Psychiatr. 1988(88):10-3.

55. Scott S, Kranz JE, Cole J, Lincecum JM, Thompson K, Kelly N, et al. Design, power, and interpretation of studies in the standard murine model of ALS. Amyotroph Lateral Scler. 2008;9(1):4-15. https://doi.org/10.1080/17482960701856300.

56. Wegorzewska I, Baloh RH. TDP-43-based animal models of neurodegeneration: new insights into ALS pathology and pathophysiology. Neurodegener Dis. 2011;8(4):262-74. https://doi.org/10. $1159 / 000321547$.

57. Wegorzewska I, Bell S, Cairns NJ, Miller TM, Baloh RH. TDP-43 mutant transgenic mice develop features of ALS and frontotemporal lobar degeneration. Proc Natl Acad Sci USA. 2009;106(44):18809-14. https://doi.org/10.1073/pnas. 0908767106.

58. Wyand MS. The use of SIV-infected rhesus monkeys for the preclinical evaluation of AIDS drugs and vaccines. AIDS Res Hum Retrovir. 1992;8(3):349-56. https://doi.org/10.1089/aid.1992.8. 349.

59. Roberts NA, Martin JA, Kinchington D, Broadhurst AV, Craig JC, Duncan IB, et al. Rational design of peptide-based HIV proteinase inhibitors. Science. 1990;248(4953):358-61.

60. Sweet A, Erickson RP, Huntington C, Dawson D. A potential animal model for studying CF heterozygote advantage: genetic variation in theophylline-inducible colonic chloride currents among inbred strains of mice. Biochem Med Metab Biol. 1992;47(1):97-102.

61. Barinaga M. Knockout mice offer first animal model for CF. Science. 1992;257(5073):1046-7.

62. Knight A, Bailey J, Balcombe J. Animal carcinogenicity studies: 3. Alternatives to the bioassay. Altern Lab Anim. 2006;34(1):39 48.

63. Knight A, Bailey J, Balcombe J. Animal carcinogenicity studies: 1. Poor human predictivity. Altern Lab Anim. 2006;34(1):19-27.

64. Ujhazy E, Mach M, Navarova J, Brucknerova I, Dubovicky M. Teratology - past, present and future. Interdiscip Toxicol. 2012;5(4):163-8. https://doi.org/10.2478/v10102-012-0027-0.

65. Hanke T. Lessons from TGN1412. Lancet. 2006;368(9547): 1569-70; author reply 70. https://doi.org/10.1016/S01406736(06)69651-7.

66. Jerie P. New catastrophe in pharmacological treatment-the crisis of clinical studies? Acute organ failure after administration of TGN1412. Casopis lekaru ceskych. 2006;145(6):426.

67. Kenter MJ, Cohen AF. Establishing risk of human experimentation with drugs: lessons from TGN1412. Lancet. 2006;368(9544): 1387-91. https://doi.org/10.1016/S0140-6736(06)69562-7.

68. Enterline PE. Early animal research on asbestos cancer. Am J Ind Med. 1993;24(6):783-5 author reply 7-91.

69. Enterline PE, Hartley J, Henderson V. Asbestos and cancer: a cohort followed up to death. Br J Ind Med. 1987;44(6):396-401.

70. Stewart A. Alternative sources of risk estimates for cancer effects of radiation. Mt Sinai J Med. 1995;62(5):380-5.

71. Gardner MJ, Snee MP, Hall AJ, Powell CA, Downes S, Terrell JD. Results of case-control study of leukaemia and lymphoma among young people near Sellafield nuclear plant in West Cumbria. BMJ. 1990;300(6722):423-9.

72. Ainley CC, Senapati A, Brown IM, Iles CA, Slavin BM, Mitchell $\mathrm{WD}$, et al. Is alcohol hepatotoxic in the baboon? J Hepatol. 1988;7(1):85-92.

73. Zbinden G, Flury-Roversi M. Significance of the LD50-test for the toxicological evaluation of chemical substances. Arch Toxicol. 1981;47(2):77-99. 
74. Ekwall B, Barile FA, Castano A, Clemedson C, Clothier RH, Dierickx P, et al. MEIC evaluation of acute systemic toxicity: part VI. The prediction of human toxicity by rodent LD50 values and results from 61 in vitro methods. Altern Lab Anim. 1998;26(Suppl 2):617-58

75. Ekwall B, Clemedson C, Crafoord B, Ekwall B, Hallander S, Walum E, et al. MEIC evaluation of acute systemic toxicity: part V. Rodent and human toxicity data for the 50 reference chemicals. Altern Lab Anim. 1998;26(Suppl 2):571-616.

76. Kelly JT, Abuzzahab FS Sr. The antiparkinson properties of amantadine in drug-induced parkinsonism. J Clin Pharmacol New Drugs. 1971;11(3):211-4.

77. Danielczyk W. Twenty-five years of amantadine therapy in Parkinson's disease. J Neural Transm Suppl. 1995;46:399-405.

78. Hubsher G, Haider M, Okun MS. Amantadine: the journey from fighting flu to treating Parkinson disease. Neurology. 2012 Apr 3;78(14):1096-9.

79. Ban TA. Fifty years chlorpromazine: a historical perspective. Neuropsychiatr Dis Treat. 2007;3(4):495-500.

80. Anisimov VN. Age and dose-dependent carcinogenic effects of Nnitrosomethylurea administered intraperitoneally in a single dose to young and adult female mice. J Cancer Res Clin Oncol. 1993;119(11):657-64.

81. Anisimov VN. Carcinogenesis and aging. III. The role of age in initiation and promotion of carcinogenesis. Exp Pathol. 1982;22(3):131-47.

82. Shanks N, Greek R, Greek J. Are animal models predictive for humans? Philos Ethics Humanit Med. 2009;4(2):2. https://doi. org/10.1186/1747-5341-4-2.

83. Bruno R, Vivier N, Montay G, Le Liboux A, Powe LK, Delumeau JC, et al. Population pharmacokinetics of riluzole in patients with amyotrophic lateral sclerosis. Clin Pharmacol Ther. 1997;62(5): 518-26. https://doi.org/10.1016/S0009-9236(97)90047-3.

84. Lidegaard O. Smoking and use of oral contraceptives: impact on thrombotic diseases. Am J Obstet Gynecol. 1999;180(6 Pt 2): S357-63.

85. Formenty P, Boesch C, Wyers M, Steiner C, Donati F, Dind F, et al. Ebola virus outbreak among wild chimpanzees living in a rain forest of Cote d'Ivoire. J Infect Dis. 1999;179(Suppl 1):S120 6. https://doi.org/10.1086/514296.

86. Pennisi E. Monkey virus DNA found in rare human cancers. Science. 1997;275(5301):748-9.

87. Reinhardt V, Roberts A. The African polio vaccine-acquired immune deficiency syndrome connection. Med Hypotheses. 1997;48(5):367-74.

88. Lucas S. The river: a journey back to the source of HIV and AIDS. BMJ. 2000;320(7247):1481A.

89. Folks TM. Chimpanzees as original source for HIV. JAMA. 2000;283(3):310.

90. Horowitz LG. Murder and cover-up could explain the Florida dental AIDS mystery. Br Dent J. 1994 Dec 10-24;177(11-12): 423-7.

91. Hayflick L. The choice of the cell substrate for human virus vaccine production. Lab Pract. 1970;19(1):58-62.

92. Hayflick L. Human virus vaccines: why monkey cells? Science. 1972;176(4036):813-4.

93. King A. The search for better animal models of Alzheimer's disease. Nature. 2018;559(7715):S13-S5. https://doi.org/10.1038/ d41586-018-05722-9.

94. Kitazawa M, Medeiros R, Laferla FM. Transgenic mouse models of Alzheimer disease: developing a better model as a tool for therapeutic interventions. Curr Pharm Des. 2012;18(8):1131-47.

95. LaFerla FM, Green KN. Animal models of Alzheimer disease. Cold Spring Harb Perspect Med. 2012;2(11). https://doi.org/10. 1101/cshperspect.a006320 .
96. Morrissette DA, Parachikova A, Green KN, LaFerla FM. Relevance of transgenic mouse models to human Alzheimer disease. J Biol Chem. 2009;284(10):6033-7. https://doi.org/10. 1074/jbc.R800030200.

97. Roher AE, Kuo YM, Kokjohn KM, Emmerling MR, Gracon S. Amyloid and lipids in the pathology of Alzheimer disease. Amyloid. 1999;6(2):136-45.

98. Kuo YM, Beach TG, Sue LI, Scott S, Layne KJ, Kokjohn TA, et al. The evolution of a beta peptide burden in the APP23 transgenic mice: implications for A beta deposition in Alzheimer disease. Mol Med. 2001;7(9):609-18.

99. Wen PH, Hof PR, Chen X, Gluck K, Austin G, Younkin SG, et al. The presenilin-1 familial Alzheimer disease mutant P117L impairs neurogenesis in the hippocampus of adult mice. Exp Neurol. 2004;188(2):224-37. https://doi.org/10.1016/j.expneurol.2004. 04.002 .

100. Avishai E, Yeghiazaryan K, Golubnitschaja O. Impaired wound healing: facts and hypotheses for multi-professional considerations in predictive, preventive and personalised medicine. EPMA J. 2017;8(1):23-33. https://doi.org/10.1007/s13167-0170081-y.

101. Dunn L, Prosser HC, Tan JT, Vanags LZ, Ng MK, Bursill CA. Murine model of wound healing. J Vis Exp. 2013;(75):e50265. https://doi.org/10.3791/50265 .

102. Balls M. Replacement of animal procedures: alternatives in research, education and testing. Lab Anim. 1994;28(3):193-211.

103. Kirk RG. Recovering the principles of humane experimental technique: the 3 Rs and the human essence of animal research. Sci Technol Human Values. 2018 Jul;43(4):622-48. https://doi.org/ 10.1177/0162243917726579.

104. Arora T, Mehta AK, Joshi V, Mehta KD, Rathor N, Mediratta PK, et al. Substitute of animals in drug research: an approach towards fulfillment of 4R's. Indian J Pharm Sci. 2011 Jan-Feb;73:1): 1-6.

105. Gordon S, Daneshian M, Bouwstra J, Caloni F, Constant S, Davies DE, et al. Non-animal models of epithelial barriers (skin, intestine and lung) in research, industrial applications and regulatory toxicology. Altex. 2015;32(4):327-78. https://doi.org/10.14573/altex. 1510051.

106. Zhang Q, Bhattacharya S, Andersen ME, Conolly RB. Computational systems biology and dose-response modeling in relation to new directions in toxicity testing. J Toxicol Environ Health B Crit Rev. 2010;13(2-4):253-76. https://doi.org/10. 1080/10937404.2010.483943 .

107. Doke SK, Dhawale SC. Alternatives to animal testing: a review. Saudi Pharm. J. 2015;23(3):223-9.

108. Lilienblum W, Dekant W, Foth H, Gebel T, Hengstler J, Kahl R, et al. Alternative methods to safety studies in experimental animals: role in the risk assessment of chemicals under the new European Chemicals Legislation (REACH). Arch Toxicol. 2008;82(4):211-36.

109. Gruber FP, Hartung T. Alternatives to animal experimentation in basic research. Altex. 2004;21:3-31.

110. Glanzer JG, Byrne BM, McCoy AM, James BJ, Frank JD, Oakley GG. In silico and in vitro methods to identify ebola virus VP35dsRNA inhibitors. Bioorg Med Chem. 2016;24(21):5388-92. https://doi.org/10.1016/j.bmc.2016.08.065.

111. Freires IA, Sardi JCO, de Castro RD, Rosalen PL. Alternative animal and non-animal models for drug discovery and development: bonus or burden? Pharm Res. 2017;34(4):681-6.

112. Mosig AS. Organ-on-chip models: new opportunities for biomedical research. Future Sci OA. 2016 Jun;3(2):FSO130. Published online 2016 Jul 6. https://doi.org/10.4155/fsoa-2016-0038 .

113. Beeson PB. The growth of knowledge about a disease: hepatitis. Am J Med. 1979;67(3):366-70.

114. Kannel WB, Castelli WP, McNamara PM, McKee PA, Feinleib M. Role of blood pressure in the development of congestive heart 
failure. N Engl J Med. 1972;287(16):781-7. https://doi.org/10. 1056/NEJM197210192871601.

115. Sytkowski PA, Kannel WB, D'Agostino RB. Changes in risk factors and the decline in mortality from cardiovascular disease. The Framingham Heart Study. N Engl J Med. 1990;322(23):1635-41. https://doi.org/10.1056/NEJM199006073222304.

116. Sekula P, Del Greco MF, Pattaro C, Kottgen A. Mendelian randomization as an approach to assess causality using observational data. J Am Soc Nephrol: JASN. 2016;27(11):3253-65. https://doi. org/10.1681/ASN.2016010098.

117. Mendelson MM, Marioni RE, Joehanes R, Liu C, Hedman AK, Aslibekyan S, et al. Association of body mass index with DNA methylation and gene expression in blood cells and relations to cardiometabolic disease: a Mendelian randomization approach. PLoS Med. 2017;14(1):e1002215. https://doi.org/10.1371/ journal.pmed.1002215.

118. Holmes MV, Lange LA, Palmer T, Lanktree MB, North KE, Almoguera B, et al. Causal effects of body mass index on cardiometabolic traits and events: a Mendelian randomization analysis. Am J Hum Genet. 2014;94(2):198-208. https://doi.org/10.1016/j. ajhg.2013.12.014.

119. Shah S, Casas JP, Drenos F, Whittaker J, Deanfield J, Swerdlow DI, et al. Causal relevance of blood lipid fractions in the development of carotid atherosclerosis: Mendelian randomization analysis. Circ Cardiovasc Genet. 2013;6(1):63-72. https://doi.org/10. 1161/CIRCGENETICS.112.963140.

120. Holmes MV, Ala-Korpela M, Smith GD. Mendelian randomization in cardiometabolic disease: challenges in evaluating causality. Nat Rev Cardiol. 2017;14(10):577-90. https://doi.org/10.1038/ nrcardio.2017.78.

121. Holmes MV, Asselbergs FW, Palmer TM, Drenos F, Lanktree MB, Nelson CP, et al. Mendelian randomization of blood lipids for coronary heart disease. Eur Heart J. 2015;36(9):539-50. https:// doi.org/10.1093/eurheartj/eht571.

122. Ahnen DJ. Are animal models of colon cancer relevant to human disease. Dig Dis Sci. 1985;30(12 Suppl):103S-6S.

123. Pories SE, Ramchurren N, Summerhayes I, Steele G. Animal models for colon carcinogenesis. Arch Surg. 1993;128(6):647-53.

124. Ali J, Dunn J, Eason M, Drumm J. Comparing the standardized live trauma patient and the mechanical simulator models in the ATLS initial assessment station. J Surg Res. 2010;162(1):7-10. https://doi.org/10.1016/j.jss.2010.02.029.

125. Gilbart MK, Hutchison CR, Cusimano MD, Regehr G. A computer-based trauma simulator for teaching trauma management skills. Am J Surg. 2000;179(3):223-8.

126. Tillander B, Ledin T, Nordqvist P, Skarman E, Wahlstrom O. A virtual reality trauma simulator. Med Teach. 2004;26(2):189-91. https://doi.org/10.1080/0142159042000192037 .

127. Bergstrom M. The use of microdosing in the development of small organic and protein therapeutics. J Nucl Med. 2017;58(8):118895. https://doi.org/10.2967/jnumed.116.188037.

128. Burt T, John CS, Ruckle JL, Vuong LT. Phase-0/microdosing studies using PET, AMS, and LC-MS/MS: a range of study methodologies and conduct considerations. Accelerating development of novel pharmaceuticals through safe testing in humans - a practical guide. Expert Opin Drug Deliv. 2017;14(5):657-72. https:// doi.org/10.1080/17425247.2016.1227786 .
129. Wotherspoon AT, Safavi-Naeini M, Banati RB. Microdosing, isotopic labeling, radiotracers and metabolomics: relevance in drug discovery, development and safety. Bioanalysis. 2017;9(23): 1913-33. https://doi.org/10.4155/bio-2017-0137.

130. Xu K-P, Li X-F, F-SX Y. Corneal organ culture model for assessing epithelial responses to surfactants. Toxicol Sci. 2000;58(2):306-14.

131. Shay JW, Wright WE. The use of telomerized cells for tissue engineering. Nat Biotechnol. 2000;18(1):22-3.

132. Hill AJ, Teraoka H, Heideman W, Peterson RE. Zebrafish as a model vertebrate for investigating chemical toxicity. Toxicol Sci. 2005;86(1):6-19.

133. Peterson RT, Nass R, Boyd WA, Freedman JH, Dong K, Narahashi T. Use of non-mammalian alternative models for neurotoxicological study. Neurotoxicology. 2008;29(3):546-55.

134. Lagadic L, Caquet $\mathrm{T}$. Invertebrates in testing of environmental chemicals: are they alternatives? Environ Health Perspect. 1998;106(Suppl 2):593-611.

135. Wilson-Sanders SE. Invertebrate models for biomedical research, testing, and education. ILAR J. 2011;52(2):126-52.

136. Gilbert LI. Drosophila is an inclusive model for human diseases, growth and development. Mol Cell Endocrinol. 2008;293(1-2): 25-31.

137. Barr MM. Super models. Physiol Genomics. 2003;13(1):15-24.

138. Madeo F, Engelhardt S, Herker E, Lehmann N, Maldener C, Proksch A, et al. Apoptosis in yeast: a new model system with applications in cell biology and medicine. Curr Genet. 2002;41(4): 208-16.

139. Karathia H, Vilaprinyo E, Sorribas A, Alves R. Saccharomyces cerevisiae as a model organism: a comparative study. PLoS One. 2011;6(2):e16015.

140. Hedges SB. The origin and evolution of model organisms. Nat Rev Genet. 2002;3(11):838-49.

141. Höfer T, Gerner I, Gundert-Remy U, Liebsch M, Schulte A, Spielmann H, et al. Animal testing and alternative approaches for the human health risk assessment under the proposed new European chemicals regulation. Arch Toxicol. 2004;78(10):54964.

142. Creech JL Jr, Johnson MN. Angiosarcoma of liver in the manufacture of polyvinyl chloride. J Occup Med. 1974;16(3):150-1.

143. Davies MR, Hruska KA. Pathophysiological mechanisms of vascular calcification in end-stage renal disease. Kidney Int. 2001;60(2):472-9.

144. Hendriksen CF. Replacement, reduction and refinement alternatives to animal use in vaccine potency measurement. Expert Rev Vaccines. 2009;8(3):313-22.

145. Dezfulian M, Bartlett JG. Selective isolation and rapid identification of Clostridium botulinum types A and B by toxin detection. $\mathrm{J}$ Clin Microbiol. 1985;21(2):231-3.

146. Flaten GE, Dhanikula AB, Luthman K, Brandl M. Drug permeability across a phospholipid vesicle based barrier: a novel approach for studying passive diffusion. Eur J Pharm Sci. 2006;27(1):80-90.

Publisher's note Springer Nature remains neutral with regard to jurisdictional claims in published maps and institutional affiliations. 